\title{
张村驿(二)水文站水面流速系数分析
}

\author{
刘意
}

延安水文水资源勘测局

DOI:10.32629/hwr.v3i7.2263

[摘 要] 张村驿水文站现用水面流速系数分析年代较远, 为了保证流量测验精度,对现用系数进行验证。根据现行《河流流量 测验规范》GB50179-2015 要求, 对张村驿站进行了水面流速系数试验分析, 分析了该站的水面流速系数, 并对分析成果进行了 合理性验证,为提高本站水面一点法流量精度提供了依据。

[关键词] 张村驿水文站; 水面流速系数; 结论

\section{1 测站基本情况及测验河段情况}

\section{1测站基本情况}

张村驿 (二) 水文站系黄河流域北洛河水系葫芦河重要 控制站, 位于陕西省延安市富县张村驿镇旗杆沟村, 控制集 水面积 $4715 \mathrm{~km}^{2}$, 距河口距离 $72 \mathrm{~km}$, 属国家重要水文站。

\section{2 测验河段情况}

测验河段顺直, 系窄深河槽, 断面呈 “U” 型, 水流平缓。 基上 $250 \mathrm{~m}$ 处为急滩, 基下 $300 \mathrm{~m}$ 处有川口支流自右岸汇入, 基 下约 $350 \mathrm{~m}$ 处修建跨河大桥一座。高水右岸发生漫滩, 主流基 本稳定, 河床由砂砾石组成, 两岸多水草。测验河段布设基本 水尺断面兼流速仪测流断面及浮标测流中断面, 上、下浮标 断面间距170m。

张村驿站处于葫芦河中游, 上游处于子午岭林区, 植被 较好, 产流较少。洪水主要由暴雨形成, 峰型肥胖, 历时较长, 历年水位流量关系线多呈单一线, 洪水含沙量较小, 水、沙峰 过程基本同步, 峰型相似。

\section{2 水面流速系数分析的必要性}

张村驿站为常年驻测水文站, 一年中的测流次数, 根据 测站水情变化情况, 合理地分布于高、中、低各级水位, 并根 据不同量级的洪水分别选用不同的测验方法, 中 (低) 水时期, 一般利用水文缆车采用流速仪施测, 当水深较小或枯水季节 时, 在保证人身安全的前提下, 勘选临时断面涉水施测。洪水 期, 视洪水具体情况而定, 在水位涨落差不大及漂浮物较少 的情况下, 用流速仪简测法施测, 否则, 采用中泓浮标法施 测。测流仪主要选用LS25-1、LS25-3型流速仪, 浮标为 “十” 字型秸杆草靶。

在进行日常流量测验中, 一般采用流速仪 0.6 一点法施 测, 有时会遇到特殊情况 (如洪水期水位变化剧烈、受水生物 影响、有分流等水流条件复杂的情况下), 当限于测流历时或 测流条件, 不能采用常测法将流速仪下放到相对位置 0.6 处 测取垂线平均流速, 只能测水面流速, 在水面漂浮物较少的 情况下, 通常以流速仪采用水面一点法施测水面流速, 然后 再乘以水面流速系数, 借用临近断面面积计算断面流量。另 外, 用浮标法测流, 影响因素较多, 变化幅度较大, 面积确定 较困难, 则有很大的任意性, 测验精度不能保证。用水力学公
式法推算流量, 除了面积确定困难外, 还存在比降和糔率的 取值问题, 同样精度也较低。

经分析, 采用流速仪水面一点法进行测验, 则可以合理 地解决以上问题。且流速仪一点法测流具有流速仪放置简 便、测流速度快、易操作等优点。测流时, 水面流速系数的 选用是否科学、合理, 直接决定流量测验的精度, 因此, 进行 水面流速系数分析十分必要。

\section{3 水面流速系数的分析}

3.1 分析资料的获取

张村驿水文站现用的水面流速系数 “ 1.15 ”, 为上世纪 八九十年代试验分析所得, 距今已年代较远。2013年河道发 生了较大洪水, 断面冲刷; 而且近几年来, 由于原1984年基下 $300 \mathrm{~m}$ 处修建的过水桥拆除, 在基下 $350 \mathrm{~m}$ 新建了跨河大桥, 下 游断面进行了河堤整修等因素, 对断面的比降、糙率有一定 的影响。为了提高流量的测验精度, 需对现用的水面流速系 数1.15进行验证。

依据现行的《河流流量测验规范》(GB50179-2015) 附录 B中B. 7. 6 第 4 条规定 “畅流期水面流速系数应由多点法测速 资料或其他加测水面流速的资料分析确定, 或根据实测的水 面比降、河床糙率等资料分析计算。” 本次分析选取了张村 驿水文站 2018 年的 9 次实际比测流量资料, 比测主要在中低 水进行, 测验均采用LS25-3A型流速仪, 共66组264个测点流 速, 最大流速 $2.42 \mathrm{~m} / \mathrm{s}$, 最小流速 $0.44 \mathrm{~m} / \mathrm{s}$; 最高水位 $927.01 \mathrm{~m}$, 最低水位 $925.58 \mathrm{~m}$, 水位变幅 $1.43 \mathrm{~m}$; 每次测验时采用垂线三 点法 $(0.2 、 0.6 、 0.8)$ 测速并加测水面流速, 然后分别计算出 断面流量和水面虚流量。

\section{2 水面流速系数的分析计算}

本次分析是用流速仪施测的垂线平均流速计算的断面 流量与水面流速计算的断面虚流量建立关系, 进行计算, 再 通过关系曲线的转换, 确定出水面流速系数; 最后将分析的 系数用于水面测流的流量计算, 并根据实测的断面流量对分 析结果进行精确性验证。

\section{2.1 算术平均法}

将2018年在不同水位级所比测的9次流量的66条测速垂 线, 分别根据流速仪的计算公式计算出每条测速垂线相对水 
深0. $0 、 0.2 、 0.6 、 0.8$ 的测点流速 $\mathrm{V}_{0.0} 、 \mathrm{~V}_{0.2} 、 \mathrm{~V}_{0.6} 、 \mathrm{~V}_{0.8}$, 然后 采用三点法计算公式 $V m=\left(V_{0.2}+V_{0.6}+V_{0.8}\right) / 3$ 计算出每条垂线的 垂线平均流速, 再计算出每条垂线平均流速和水面流速的比 值 $\mathrm{Vm} / \mathrm{V}_{0.0}$, 得出每条垂线的水面流速系数, 最后取其均值, 得 出断面平均水面流速系数为 1.0309 。

再分别用垂线平均流速 $V m$ 计算出断面流量 $\mathrm{Q}$, 用水面流 速 $\mathrm{V}_{0.0}$ 计算出断面虚流量 $\mathrm{Q}_{0}$, 然后计算出断面流量 $\mathrm{Q}$ 和断面虚 流量 $\mathrm{Q}_{0}$ 的比值, 即 $\mathrm{K}=\mathrm{Q} / \mathrm{Q}_{0}$, 求得各次的断面平均水面流速系数, 取其平均值, 详见表 1 :

表1 张村驿站水面流速系数分析计算表

\begin{tabular}{|c|c|c|c|c|c|}
\hline 测次 & $\begin{array}{l}\text { 水位 } \\
\text { (m) }\end{array}$ & $\begin{array}{l}\text { 断面流量 } \\
Q\left(\mathrm{~m}^{3} / \mathrm{s}\right)\end{array}$ & $\begin{array}{c}\text { 断面虚流量 } \\
Q_{0}\left(\mathrm{~m}^{3} / \mathrm{s}\right)\end{array}$ & $Q / Q_{0}$ & 平均系数 $\mathrm{K}$ \\
\hline 13 & 925.75 & 14.4 & 13.1 & 1.0992 & \multirow{9}{*}{ 1. 0272} \\
\hline 14 & 925.59 & 10.2 & 10.3 & 0.9903 & \\
\hline 18 & 926.35 & 36.9 & 34.4 & 1. 0727 & \\
\hline 21 & 926.4 & 36.8 & 37.1 & 0.9919 & \\
\hline 23 & 926.09 & 25.3 & 25.5 & 0.9922 & \\
\hline 26 & 926.99 & 68 & 67.1 & 1. 0134 & \\
\hline 39 & 926.85 & 64.1 & 58.4 & 1. 0976 & \\
\hline 40 & 926.36 & 37 & 36.7 & 1. 0082 & \\
\hline 43 & 926.28 & 33.8 & 34.5 & 0.9797 & \\
\hline
\end{tabular}

上面经过分别计算出垂线平均流速和水面流速的比值 $\mathrm{Vm} / \mathrm{V}_{0.0}$ 、断面流量 $\mathrm{Q}$ 和断面虚流量 $\mathrm{Q}_{0}$ 的比值 $\mathrm{Q} / \mathrm{Q}_{0}$, 用算术平均 法计算出两次的平均系数 $K$ 分别为 $1.0309 、 1.0272$, 系数值非 常接近, 经过四舍五入后, 初步确定水面流速系数为 1.03 。

\subsection{2回归线分析法}

将各个分析测次分别以断面流量 $\mathrm{Q}$ 为纵坐标, 以断面虚 流量 $\mathrm{Q}_{0}$ 为横坐标, 点绘 $\mathrm{Q}-\mathrm{Q}_{0}$ 相关关系图进一步分析, 如下图 1 :

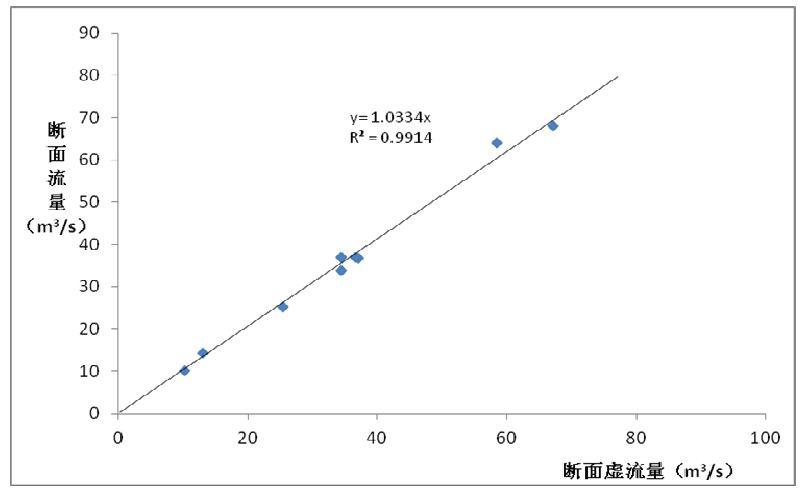

图1 断面流量 ${ }^{\sim}$ 断面虚流量相关关系图

通过关系图可以看出, 各个分析测次的 $Q / Q_{0}$ 值较为稳定, 可通过点子中心与原点绘一条直线, 该直线的斜率即为所求 的断面平均水面流速系数, 得出相关方程即:

$\mathrm{Q}=1.03 Q_{0}$
$\mathrm{R}^{2}=0.992$

式中: Q一断面流量

$Q_{0}$ 一断面虚流量

$\mathrm{R}$ 一相关系数

从以上拟定的曲线和方程公式中得出相关系数 $R^{2}=$
$0.992, R$ 表示相关变量之间的密切程度, 当 $R^{2}$ 越接近 1 , 说明 变量误差越小, 直线拟合的程度越好, $Q Q_{i}$ 与 $Q_{0}$ 的相关关系越 好, 因此, 得出直线的斜率 $K=1.03$, 即水面流速系数为 1.03 。

3.3 对分析成果进行验证

通过以上算术平均法计算和回归线法的分析, 得出张村 驿站水面流速系数为 1.03 , 现根据比测试验的流量资料对分 析成果进行合理性检验, 用分析得出的水面流速系数 1.03 计 算出水面一点法所测的流量 $Q_{i}$, 计算出 $Q$ 与 $Q_{i}$ 的相对误差, 并 计算出置信水平为 $95 \%$ 的随机不确定度和系统误差。

3. 3. 1水面流速的随机不确定度采用如下公式进行计算, 计算表见下表 2 :

$\mathrm{K}=\mathrm{Q} / \mathrm{Q}_{0}$

$$
X^{\prime}=2\left[\frac{1}{n-1} \sum\left(\frac{Q-Q i}{0 i}\right)^{2}\right]^{\frac{1}{2}}
$$

式中 $\mathrm{K}$ 一一水面流速系数

Q-一断面流量 (采用三点法施测)

$Q_{0}$ 一一断面虚流量 (水面一点法施测)

$Q_{i}$-一用水面测点流速乘以水面系数所得流量

$\mathrm{n}$-一实测流量次数

3. 3. 2水面流速系数的系统误差采用下式计算

$$
\eta=\sum\left(\frac{Q-Q i}{Q i}\right) / n * 100 \%
$$

式中 $\eta$ ——系统误差。

表2＼cjkstart张村驿站水面流速系数随机不确定度计算表

\begin{tabular}{|c|c|c|c|c|c|}
\hline 序号 & $Q_{0}\left(\mathrm{~m}^{3} / \mathrm{s}\right)$ & $Q\left(\mathrm{~m}^{3} / \mathrm{s}\right)$ & $Q_{\mathrm{i}}\left(\mathrm{m}^{3} / \mathrm{s}\right)$ & {$\left[\left(\mathrm{Q}-\mathrm{Q}_{\mathrm{i}}\right) / \mathrm{Q}_{\mathrm{i}}\right] * 100$} & $\left\{\left[\left(\mathrm{Q}-\mathrm{Q}_{\mathrm{i}}\right) / \mathrm{Q}_{\mathrm{i}}\right] * 100\right\}^{2}$ \\
\hline 1 & 13.3 & 14.4 & 13.7 & 6.66 & 44.44 \\
\hline 2 & 10.3 & 10.2 & 10.6 & -3.77 & 14.24 \\
\hline 3 & 34.4 & 36.9 & 35.4 & 4.24 & 17.95 \\
\hline 4 & 37.1 & 36.8 & 38.3 & -3.92 & 15.34 \\
\hline 5 & 25.5 & 25.3 & 26.2 & -3.44 & 11.80 \\
\hline 6 & 67.1 & 68 & 69.4 & -2.02 & 4.07 \\
\hline 7 & 58.4 & 64.1 & 60.1 & 6.66 & 44.30 \\
\hline 8 & 36.7 & 37 & 37.8 & -2.12 & 4.48 \\
\hline 9 & 34.5 & 33.8 & 35.4 & -4.52 & 20.43 \\
\hline \multicolumn{7}{|c|}{$\sum\left\{\left[\left(\mathrm{Q}-\mathrm{Q}_{\mathrm{i}}\right) / \mathrm{Q}_{\mathrm{i}}\right] * 100\right\}=-2.22$} & $\sum\left\{\left[\left(\mathrm{Q}-\mathrm{Q}_{\mathrm{i}}\right) / \mathrm{Q}_{\mathrm{i}}\right] * 100\right\}^{2}=177.05$ \\
\hline \multicolumn{7}{|c|}{ 随机不确定度 $X^{\prime}{ }_{\mathrm{Q}}=9.4$} & 系统误差 $=-0.2$ \\
\hline
\end{tabular}

经过误差计算, 水面流速系数的随机不确定度为 $9.4 \%$, 系 统误差为 $-0.2 \%$, 规范中没有明确规定出流速仪水面流速系数 的误差, 但是根据《河流流量测验规范》第6.1.1条流量比测 试验其成果精度可通过误差试验资料或比测试验资料分析评 定, 其单次流量的测验精度指标应满足流速仪单次流量测验 允许误差, 张村驿为二类精度水文站, 其在分析计算时在中低 水的允许误差为 $8 \%{ }^{\sim} 10 \%$, 系统误差为 $-2.5^{\sim} 1$ 。而张村驿站根据 比测资料计算出的随机不确定度和系统误差均在规定范围内, 因此, 证明张村驿站水面流速系数1.03是合理的。

\section{4 结语}

本次是按照《河流流量测验规范》要求对张村驿水文站 


\section{三维技术与 BIM 在水利设计行业的应用现状}

马瑶

河南省水利勘测设计研究有限公司四川分公司

DOI:10.32629/hwr.v3i7.2270

[摘 要] 如今,我国科学技术发展水平显著提高,三维设计和 BIM 技术也在我国的多个行业中得到了广泛应用,其在水利设计 行业中发挥出了十分重要的作用。但是其在技术标准和发展规划上依然有待完善,本文主要分析了三维技术与 BIM 在水利设 计行业的应用现状, 以供参考。

[关键词] 三维技术; BIM；水利设计；应用现状

BIM技术是甩图板和三维设计技术后出现的又一项新技 术。在水利工程设计中应用三维技术与BIM技术, 可全面提高 水利工程设计的质量和效率。现阶段, 三维技术与BIM技术依 然有较大的发展空间, 技术的完善也为水利设计行业的发展 创造了良好的发挥空间。

\section{1 三维技术与 BIM 技术概述}

BIM技术是建筑信息模型的简称, 其是以三维数字技术 为前提, 利用信息化模型在建筑整个寿命周期中应用的一种 现代化技术。三维技术在航天、电力和建筑行业当中均已普 及。如今, 计算机软硬件技术不断发展, BIM理念在诸多领域 也得到了推广, 且其在多种工程生命周期中的应用产生了较 高的综合效益。

水利工程是民生工程中的一种, 工程施工所面临的地质 条件十分复杂, 涉及到诸多的专业。BIM技术在水利工程设计 中的应用时间不长, 但其有着十分广阔的应用空间。三维数 字化协同设计在BIM技术中的应用十分重要, 其可显著提高 水利工程的信息化水平, 保证管理质量。

\section{2 三维技术在水利工程设计中的应用现状}

21 世纪后, 我国三维技术水平显著提高, 水利设计行业 中的部分单位和企业也感受到了时代的变化, 对此做出了一 定的调整, 加大了技术应用的研究力度, 也获得了一些成果。 但是很多企业在发展中由于资金和投入因素的影响, 依然处 于二维向三维转型的阶段。在三维协同设计和仿真技术应用 上依然存在诸多不足。很少有单位真正地应用BIM技术推动 信息化的发展, 应用的单位多为行政主管职能及规模较大的 设计单位。

如今, 市场上应用较为广泛的三维设计工具主要有Auto desk系列软件、Catia、Bentley的Architecture系列和Archi $\mathrm{CAD}$ 等, 在上述软件中前两个软件应用较为普遍。Autodesk 系列软件由于具有二维CAD的延续性, 且产品类型较多, 在国 内的水利工程设计中得到了大范围应用, 且中小规模的设计 单位对此十分青睐, 该软件出现后以较短的时间大范围普及, 具有明显的代表性。

上述软件均在新世纪元年进入中国市场, 前期三维模型
断面水面流速系数进行分析计算, 分析的资料选取了2018年 在中低水时比测的资料, 根据张村驿站的实际情况, 水面一 点法测速在中低水中运用较多, 高水时多采用浮标测速, 因 此, 此次分析选取资料具有一定的代表性、实用性。

本次分析先采用算术平均法计算出张村驿站断面平均 水面流速系数, 再利用回归线法建立流量相关关系图对系数 进一步分析, 最后对分析成果进行随机不确定度和系统误差 计算验证, 经过分析验证, 成果更加合理, 最终确定出张村驿 站的水面流速系数为 1.03 。

\section{5 问题与建议}

本次张村驿水面流速系数分析主要是对原分析系数 1. 15 进行验证, 经分析, 系数为 1.03 , 与现用的系数有较大差 异, 可能是 “ 1.15 ” 的系数分析年代较远, 河道断面发生了变 化, 原系数已失去代表性, 不能满足目前的测验需要。

本次分析的水面流速系数 1.03 , 超出了水文测验手册 (P214) 表3-9水面流速系数K1值表的参考值范围, 主要是由 于张村驿站河道断面两岸为滩地, 主河槽为较规则的“U型”,
河底较平整, 实际断面形状更接近一个矩形明渠断面, 加之 两岸岸边水草较茂密, 使水流阻力增大, 最大流速从水面转 向水面以下, 水面流速往往不是最大的。

通过对张村驿站水面系数的分析, 为张村驿站采用水面 一点法抢测流量时流速系数的选用提供了可靠的参考依据, 对提高流量资料的精度有着直接影响。由于本次分析的资料 测次偏少, 而且缆道测洪能力有限, 水位变幅范围较小, 可能 对分析成果有一定的影响。因此, 建议张村驿站可在以后的 流量测验工作中多积累一些水面系数的比测资料, 以做好对 水面系数的验证工作。

\section{[参考文献]}

[1]克斯尔・卡合曼,谢葆.流量测验流速仪法流量总不确 定度的计算[J].地下水,2014,36(03):133-134.

[2]张雪. 水文资料整编工作探析 [J]. 黑龙江科 学,2016,7(20):148-149.

[3] 耿毅. 水文资料整编合理性分析 [J]. 科技展 望,2016,26(36):145.

Copyright (c) This word is licensed under a Commons Attibution-Non Commercial 4.0 International License. 